\title{
Time-based capnography detects ineffective triggering in mechanically ventilated children
}

\author{
Robert G. T. Blokpoel ${ }^{1 *}$ (D, Alette A. Koopman', Jefta van Dijk', Frans H. C. de Jongh², \\ Johannes G. M. Burgerhof ${ }^{3}$ and Martin C. J. Kneyber ${ }^{1,3,4}$
}

To the Editor,

Ineffective triggering has been associated with an increased morbidity although a direct cause-effect relationship remains to be determined [1]. The ability of physicians to detect these events, merely using ventilator flow- and pressure-time scalars, was demonstrated to be quite low [2]. Several attempts have been made to automatically quantify patient-ventilator interaction, but most methods require monitoring additional signals, e.g. the electrical activity of the diaphragm or the oesophageal pressure $[3,4]$. As time-based capnography is recommended for routine monitoring in ventilated patients and thus easily available, we sought to explore if ineffective patient inspiratory efforts could also be recognised in the time-based capnogram, providing the physician an additional tool for recognising ineffective triggering at the bedside.

For this purpose, we studied two cohorts. The first cohort was a retrospective analysis of previous collected data in which patient-ventilator interaction was quantified [5]. Patients in the first study cohort underwent a 5-min recording of the ventilator flowtime and pressure-time scalars, electrical activity of the diaphragm (dEMG) and time-based capnogram. In the second prospective cohort, patients underwent a 5-min recording of the ventilator flow-time, pressuretime, oesophageal pressure (Poes) and time-based capnogram. In both cohorts, patient ineffective trigger efforts (i.e. increase in dEMG or a negative deflection in the Poes without cycling the ventilator) were correlated with deflections in phase III or the $\beta$-angle of the time-based capnogram.

\footnotetext{
*Correspondence: r.g.t.blokpoel@umcg.nl

${ }^{1}$ Department of Paediatrics, Division of Paediatric Intensive Care, Beatrix Children's Hospital, University Medical Center Groningen, University of Groningen, Internal Postal Code CA 62, P.O. Box 30.001, 9700 RB Groningen, the Netherlands

Full list of author information is available at the end of the article
}

Fifty-five patients (34 boys, 21 girls) were analysed. Forty-one (75\%) were admitted because of respiratory failure. Median age was $3.6[1.6-16.0]$ months and median weight 6.0 [4.6-9.5] kg. Patients had been ventilated for a median of 3.8 [2.3-5.3] days before being studied. In $84 \%$ (46), patients were ventilated using a pressure $\mathrm{A} / \mathrm{C}$ mode of ventilation. In the first cohort, 3823 breaths were analysed. One hundred and fifty-five of 213 trigger errors were recognisable in the flow- and pressure-time scalars, dEMG tracing and time-based capnogram (sensitivity $72.77 \%$, specificity of $99.97 \%$ ). There were no negative deflections recognised in the time-based capnogram in 50/58 (27\%) events because the flow remained $<0 \mathrm{~L} / \mathrm{min}$. In the second cohort, 5365 breaths were analysed. Five hundred and thirty-seven of the 555 trigger errors were recognised in the time-based capnogram and the flow-, airway pressure- and oesophageal pressure-time scalars (sensitivity $96.76 \%$, specificity $99.92 \%$ ). In this cohort, there were no negative deflections visible in the time-based capnogram in 16/18 (3.24\%) events because the flow remained $<0 \mathrm{~L} / \mathrm{min}$.

To our best knowledge, this is the first paediatric report that trigger errors can be detected in the time-based capnogram. When comparing deflections in the timebased capnogram against patient neural breathing drive (i.e. $\mathrm{dEMG}$ ) and muscle effort (i.e. Poes), we found that if a patient was able to generate an inspiratory flow $>0$ $\mathrm{L} / \mathrm{min}$ that also became positive during the expiratory phase, deflections in the time-based capnogram identified ineffective triggering (Figs. 1 and 2). The caveat with this method is that trigger errors could not be picked up if the flow did not become positive. This may be overcome by taking the degree of negative deflections in the Poes measurements into account. Therefore, we think this is a promising approach that warrants further investigation. 

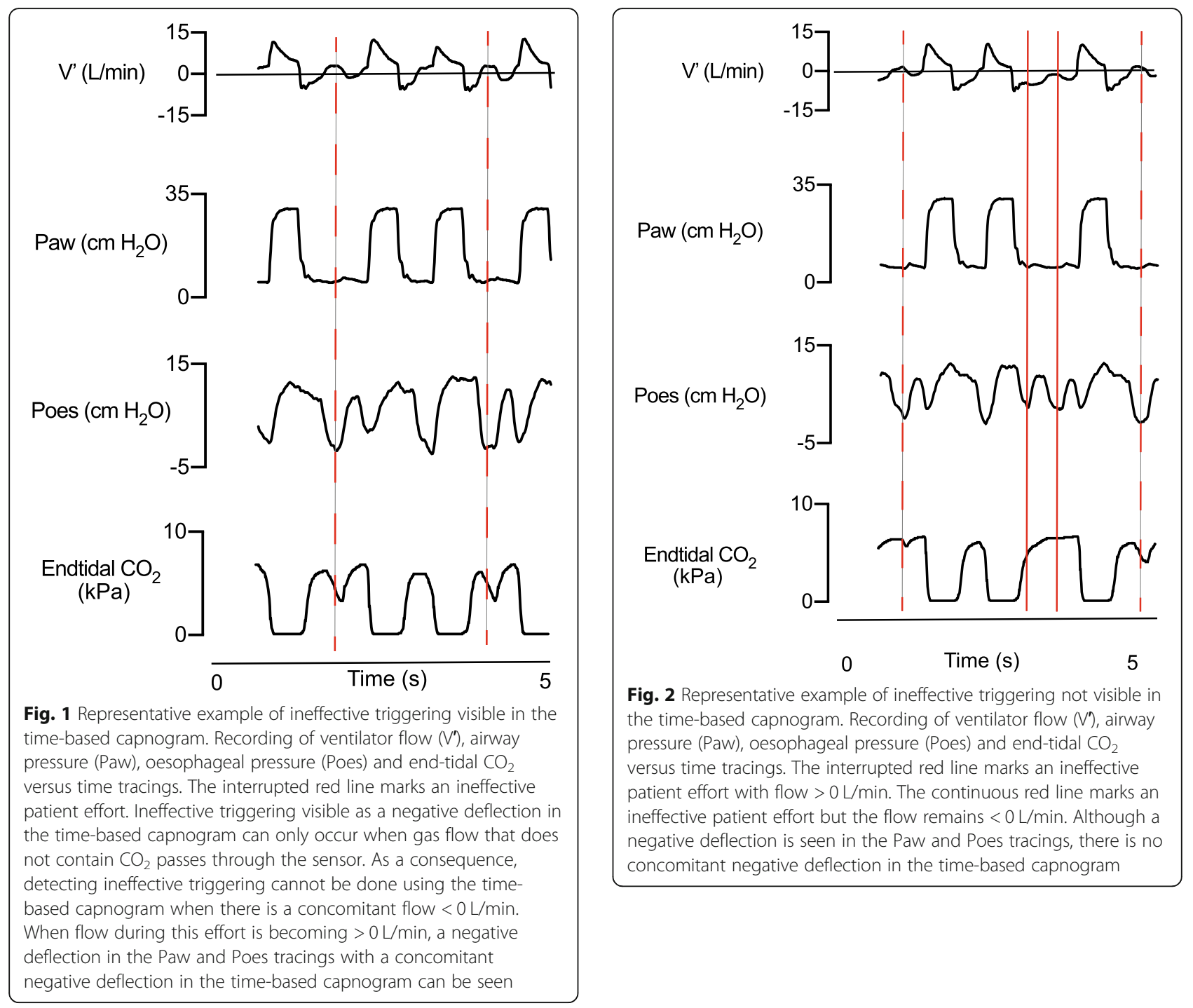


\section{Abbreviations}

dEMG: Transcutaneous measured electrical activity of the diaphragm;

Poes: Oesophageal pressure

\section{Authors' contributions}

AAK and RGTB analysed the data. AAK, RGTB and JVD collected the data. RGTB drafted the manuscript. JB contributed to the statistical analysis and provided intellectual content to the manuscript. FdJ advised on signal (i.e. dEMG, time-based capnogram, oesophageal pressure) analysis and provided intellectual content to the manuscript. MK supervised the study and is responsible for the final version of the manuscript. All authors read and approved the final manuscript.

\section{Funding}

Not applicable.

\section{Availability of data and materials}

The datasets analysed during the current study are available from the corresponding author on reasonable request.

\section{Ethics approval and consent to participate}

The Institutional Review Board, University Medical Center Groningen Medical Ethics Review Committee, approved the study. Signed informed consent was obtained from both parents or legal caretakers.

\section{Consent for publication}

Not applicable.

\section{Competing interests}

The authors declare that they have no competing interests.

\section{Author details}

'Department of Paediatrics, Division of Paediatric Intensive Care, Beatrix Children's Hospital, University Medical Center Groningen, University of Groningen, Internal Postal Code CA 62, P.O. Box 30.001, 9700 RB Groningen, the Netherlands. ${ }^{2}$ Faculty of Science and Technology, University of Twente, Enschede, the Netherlands. ${ }^{3}$ Department of Epidemiology, University Medical Center Groningen, University of Groningen, Groningen, the Netherlands. ${ }^{4}$ Critical care, Anesthesiology, Peri-operative and Emergency medicine (CAPE), University of Groningen, Groningen, the Netherlands.

\section{Received: 3 June 2019 Accepted: 27 August 2019}

\section{Published online: 04 September 2019}

\section{References}

1. de Wit M, Miller KB, Green DA, Ostman HE, Gennings C, Epstein SK. Ineffective triggering predicts increased duration of mechanical ventilation. Crit Care Med. 2009:37(10):2740-5.

2. Colombo D, Cammarota G, Alemani M, Carenzo L, Barra FL, Vaschetto R, Slutsky AS, Della Corte F, Navalesi P. Efficacy of ventilator waveforms observation in detecting patient-ventilator asynchrony. Crit Care Med. 2011; 39(11):2452-7.

3. Sinderby C, Liu S, Colombo D, Camarotta G, Slutsky AS, Navalesi P, Beck J. An automated and standardized neural index to quantify patient-ventilator interaction. Crit Care. 2013;17(5):R239.

4. Doorduin J, Sinderby CA, Beck J, van der Hoeven JG, Heunks LM. Automated patient-ventilator interaction analysis during neurally adjusted non-invasive ventilation and pressure support ventilation in chronic obstructive pulmonary disease. Crit Care. 2014;18(5):550.

5. Koopman AA, Blokpoel RGT, van Eykern LA, de Jongh FHC, Burgerhof JGM Kneyber MCJ. Transcutaneous electromyographic respiratory muscle recordings to quantify patient-ventilator interaction in mechanically ventilated children. Ann Intensive Care. 2018;8(1):12.

\section{Publisher's Note}

Springer Nature remains neutral with regard to jurisdictional claims in published maps and institutional affiliations. 